\title{
A Study To Assess The Effectiveness of Abdominal Exercise on Gastric Motility Among Post Operative Patients In Selected Hospitals, Erode District, Tamilnadu.
}

\author{
Mr. P. Anila ${ }^{1}$ \\ (Research scholar, JJTU, Rajasthan, India)
}

\begin{abstract}
:
Background: Hypomotility of the GI tract in the absence of obstruction is the hallmark of an ileus. Postoperative ileus predictably occurs after abdominal surgery. This study was performed to improve the gastric motility after abdominal exercise.

Aim: To assess the effectiveness of abdominal exercise on gastric motility among post operative patients. Design: Quasi experimental - post test only control group design.

Setting: Lotus hospital and research center and Kumarasamy hospital, Erode.

Participants: Thirty post operative patients were selected by using purposive sampling method among those who fulfill the sampling criteria.

Methods: 15 post operative patients were experimental group and 15 were control group. Only the experimental group patients received abdominal exercise. Modified gastric motility assessment scale on gastric motility was used to assess the effectiveness of abdominal exercise.

Results: From the findings of this study it can be concluded that the percentage of patients were in the age group 30-44 years, 50\% of patients were males and 50\% of them were females, most of them were educated and majority of the patients had undergone appendicectomy. In experimental group the overall mean score of gastric motility (11.6 \pm 1.62$)$ which was $97 \%$ whereas in control group the mean score was $(7.46 \pm 1.77)$ which was $62 \%$. It reveals the difference of $35 \%$. Unpaired ' $t$ ' test score was 6.8 at the level of significant $(P=0.05)$. Highly significant difference was found between the post test scores of experimental and control group. No significant association between the demographic variables and post test scores of experimental group of post operative patients, i.e. age, gender, educational status and type of surgery.

Conclusion: Abdominal exercise was highly effective in improving the gastric motility of the post operative patients. Therefore abdominal exercise can be used as a safe and effective method to improve gastric motility.
\end{abstract}

\section{Introduction}

Diseases have existed as long as mankind. Indeed surgery was practiced, even during pre history times. Before the second century, surgery was not even considered to be entity. In the present century, advanced technologies have been developed in the surgical emporium. At present Laparoscopic Surgery has more or less replaced the conventional surgery. Since the advent of Laparoscopic Surgery, we have been able to decrease the cost of treatment, shorten the hospital stay, minimize the surgical trauma; it has definitely helped in diagnosing and treating the most difficult cases with ease and confidence.

The surgical procedures and anesthesia plays the patient at risk for several complications or adverse events. The most common post operative discomforts are nausea, vomiting, restlessness, sleeplessness, thirst, constipation, flatulence and pain.Exercise stimulates postprandial motor activity in the stomach and small bowel, and this effect was related to the intensity of exercise. An abdominal exercise is easy to do and does not usually require equipment. Abdominal exercises are one of the most important types of exercises.

According to the National Center for Health Statistics of the U.S. Centers for Disease Control (CDC), in 2000 over 40 million inpatient surgical procedures were performed in the United States. Statistically, women were more likely to have surgery, accounting for $58 \%$ of ambulatory and inpatient procedures. This data includes both emergency and elective procedures.Today cholecystectomy is the most common elective operation performed by general surgeons throughout the western world. It is estimated that some 40,000 cholecystectomies are performed annually in England and a quarter for a million each year in the United States.Simon.P, (2004), reported that over 2,60,000 hospital admissions are undergoing surgery. In meta analysis of epidemiological studies of India. He was reported that about $35 \%$ to $39 \%$ of patients were affected by complication after abdominal surgery. Clemnt. A, (2005), stated that pre operative teaching combined with post operative exercise helps the patients to wear of physiological effects of anesthesia, stimulates peristalsis movements and reduce the post operative complications like pneumonia, circulatory problems. It increases the ventilation and reduces the post operative abdominal distension. Researcher identified abdominal exercise as effective to improve the gastric motility of post operative patient, there by preventing one of the major complications like paralytic ileus.

Objectives of the Study

1. To assess gastric motility among post operative patients in experimental and control group after abdominal exercise.

2. To compare the effectiveness of abdominal exercise on gastric motility among post operative patients in experimental group with control group.

3. To find out the association between post test scores of gastric motility among experimental group of post operative patients with their selected demographic variables. 
RESEARCH APPOACH

\section{Methods}

An quantitative approach was adopted for the study.

DESIGHN

Quasi experimental design more specifically Post test only control group design was used for the present study.

SETTIING OF THE STUDY

The study was conducted in Lotus Hospital \& Research Centre, Erode and kumarasamy Hospital in Erode.

VARIABLES

1. Independent variable - Abdominal exercises.

2. Dependent variable - Gastric motility among post operative patients.

\section{POPULATION}

The population for the present study was Post operative patients.

SAMPLE

The sample for the present study was post operative patients who undergone selected laparoscopic surgery in Lotus hospital \& Research Centre and Kummarasamy Hospital, Erode.

SAMPLE SIZE

The total sample size was 30 samples, out of which 15 were experimental group and 15 were control group.

\section{SAMPLING TECHNIQUE}

Purposive sampling technique was selected for the present study.

\section{DEVELOPMENT OF THE TOOL}

The tool which consist of two sections. They were,

Section A It consists demographic characteristics of post operative patients, such as Age, Gender, Education and type of surgery

Section B It consists of Modified Gastric Motility assessment Scale to assess the gastric motility of post operative patients.

\section{DATA COLLECTION PROCEDURE}

\section{Permission from the concern authority}

Prior to data collection permission was obtained from the Dean of Lotus Hospital \& Research Center and Kumarasamy Hospital, Erode.

\section{Period of data collection}

The data was collected from 14/08/2015 to 16/09/2015 for the period of one month. The investigator collected data from the both control and experimental group.

Implementation of abdominal exercise

Abdominal exercise given to the laparoscopic post operative patients in Lotus Hospital \& Research centre, Erode and Kumarasamy Hospital, Erode. The duration of exercise was given at 20 minutes for twice a day for 2 days.

Evaluation of abdominal exercise (Post test)

Modified gastric motility assessment scale was used to assess the gastric motility among post operative patients after 2 days of abdominal exercise intervention.

\section{PLAN FOR DATA ANALYSIS}

- Assess gastric motility among control and experimental group of post operative patients after abdominal exercise is analyzed by using frequency and percentage.

- Compare the effectiveness of abdominal exercise on gastric motility among post operative patients in experimental group with control group is analyzed by using unpaired $t$ test, mean, standard deviation and mean percentage.

- Find out the association between post test scores of gastric motility among experimental group of post-operative patients with their selected demographic variables is analyzed by using chi-Square test

\section{Ethical Consideration}

The research proposal was approved by the Institutional Human Ethics Committee of Dhanvantri College of Nursing Erode, Tamil Nadu. A written permission was obtained from the principal and ethical committee. The investigator explained about the study to the students and obtained written consent prior to the data collection.

\section{Results And Discussion.}

Table 1: Frequency and percentage distribution of samples according to their demographic variables

\begin{tabular}{|c|c|c|c|c|c|}
\hline \multirow[t]{2}{*}{ S.No } & \multirow{2}{*}{$\begin{array}{l}\text { Demographic } \\
\text { Variable }\end{array}$} & \multicolumn{2}{|c|}{ Experimental group $(\mathrm{n}=15)$} & \multicolumn{2}{|c|}{$\begin{array}{c}\text { Control group } \\
(\mathrm{n}=15)\end{array}$} \\
\hline & & Frequency (n) & Percentage (\%) & Frequency (n) & Percentage (\%) \\
\hline 1 & $\begin{array}{l}\text { Age in year } \\
\text { a. } \quad 19-32\end{array}$ & 7 & 47 & 4 & 27 \\
\hline & $33-46$ & 3 & 20 & 8 & 53 \\
\hline & $47-60$ & 5 & 33 & 1 & 7 \\
\hline & $61-74$ & 0 & - & 2 & 13 \\
\hline 2 & $\begin{array}{ll}\text { Gender } & \\
\text { a. } & \text { Male }\end{array}$ & 10 & 67 & 5 & 33 \\
\hline & b. $\quad$ Female & 5 & 33 & 10 & 67 \\
\hline 3 & $\begin{array}{l}\text { Educational status } \\
\begin{array}{ll}\text { a. } & \text { No formal education }\end{array}\end{array}$ & 2 & 13 & 2 & 13 \\
\hline
\end{tabular}


A study to assess the Effectiveness of Abdominal exercise on Gastric motility among Post operative ..

\begin{tabular}{|c|c|c|c|c|c|}
\hline \multirow[t]{6}{*}{ S.No } & \multirow{2}{*}{$\begin{array}{l}\text { Demographic } \\
\text { Variable }\end{array}$} & \multicolumn{2}{|c|}{ Experimental group $(n=15)$} & \multicolumn{2}{|c|}{$\begin{array}{c}\text { Control group } \\
(n=15)\end{array}$} \\
\hline & & Frequency (n) & Percentage (\%) & Frequency (n) & Percentage (\%) \\
\hline & Primary education & 2 & 13 & 6 & 40 \\
\hline & High school education & 6 & 40 & 1 & 7 \\
\hline & Higher secondary education & 2 & 14 & 1 & 6 \\
\hline & Graduation & 3 & 20 & 5 & 34 \\
\hline \multirow[t]{4}{*}{4} & $\begin{array}{l}\text { Type of surgery } \\
\text { a. } \quad \text { Appendicectomy }\end{array}$ & 7 & 47 & 7 & 47 \\
\hline & Cholecystectomy & 4 & 27 & 5 & 33 \\
\hline & Oophorectomy & 2 & 13 & 0 & - \\
\hline & $\begin{array}{l}\text { d. Laparoscopic assisted vaginal } \\
\text { hysterectomy }\end{array}$ & 2 & 13 & 3 & 20 \\
\hline
\end{tabular}

Distribution of experimental and control group samples according to their age groups depicts that, in experimental group the highest percentage $(47 \%)$ of post operative patients were in the age group of 19-32 years and the lowest percentage (20\%) of post operative patients were in the age group of 47-60 years. In control group highest percentage (53\%) of them were in the age group of 33-46 years and the lowest percentage (7\%) of them were in the age group of 47-60 years. It depicts that the highest percentage of post operative patients were in the age group of 19-32 years and 33-46 years respectively, (Fig 1). According to their gender depict that, in experimental group the highest percentage $(67 \%)$ of post operative patients were males and the lowest percentage (33\%)of post operative patients were female. In control group the highest percentage $(67 \%)$ of post operative patients were females and the lowest percentage $(33 \%)$ of post operative patients were males, (Fig 2). According to the education reveals that, in experimental group the highest percentage (40\%) of the post operative patients were high school education and similarly the lowest percentage (13\%) of post operative patients were no formal education, primary education and higher secondary education. In control group the highest percentage (40\%) of post operative patients were primary education and the lowest percentage $(7 \%)$ of post operative patients were high school education and higher secondary education, (Fig 3). According to the type of surgery reveals that, the highest percentage (47\% and $47 \%$ ) of the post operative patients had undergone appendectomy in both the group and the lowest percentage (13\% and 20\%) of post operative patients had undergone Oophorectomy and laparoscopic assisted vaginal hysterectomy respectively, (Fig 4).

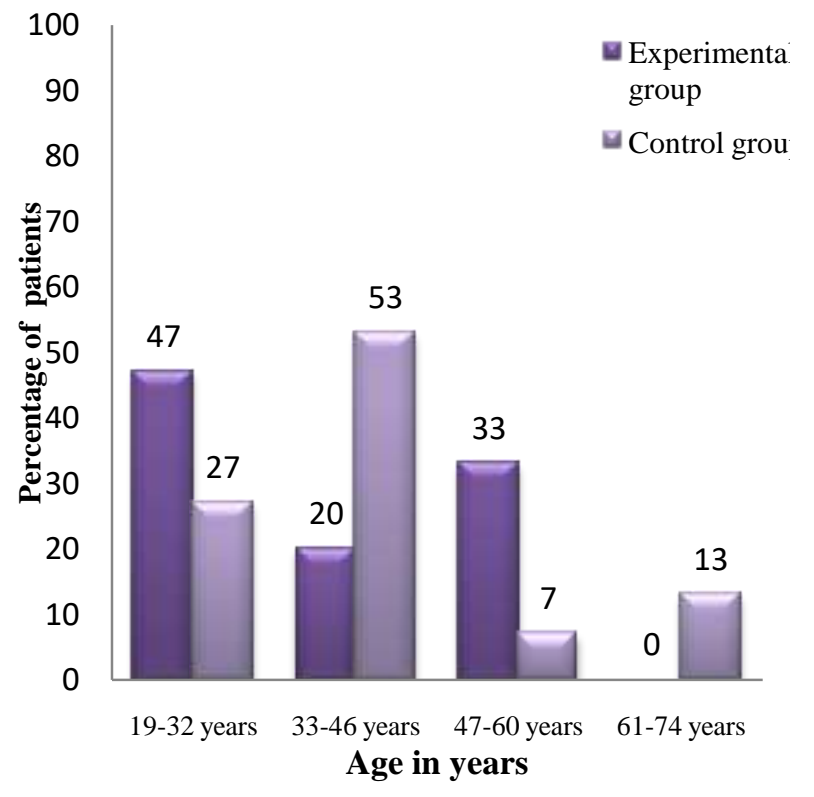

Fig 1: Bar diagram showing the distribution of control and experimental group samples according to their age group

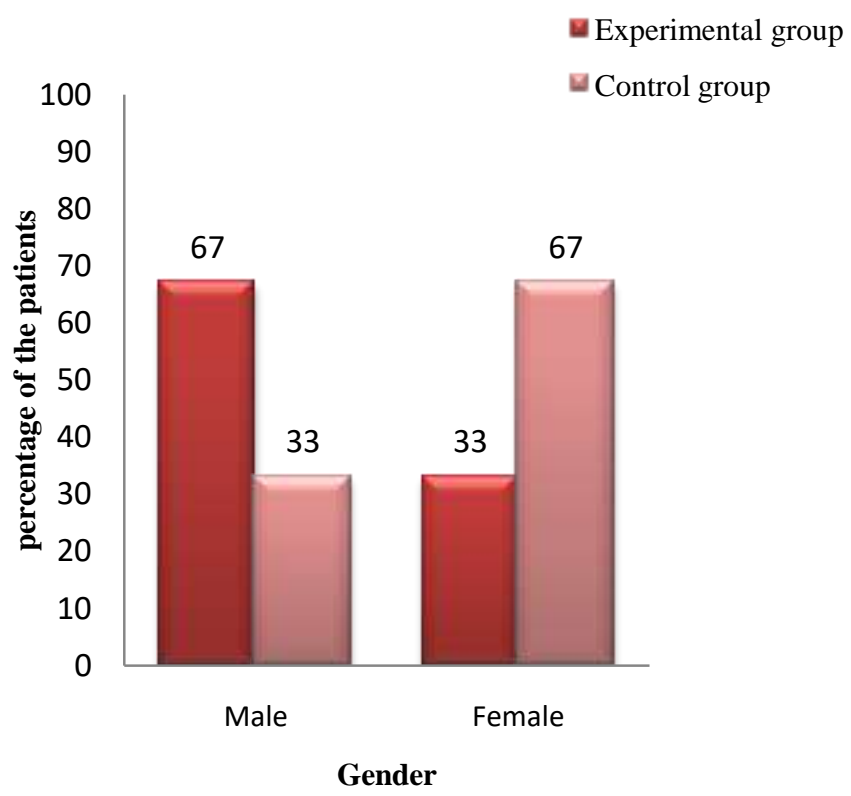

Fig 2: Bar diagram showing the distribution of control and experimental group samples according to their gender. 


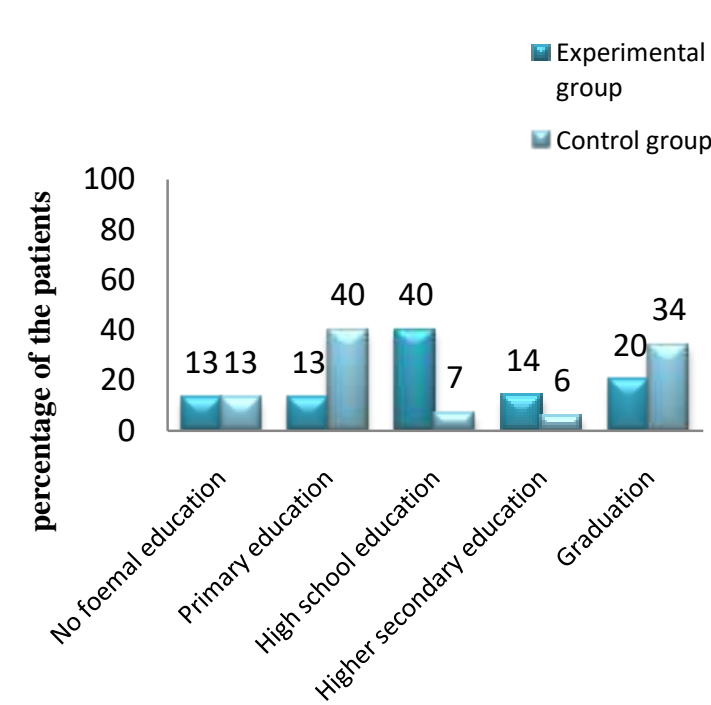

Educational status

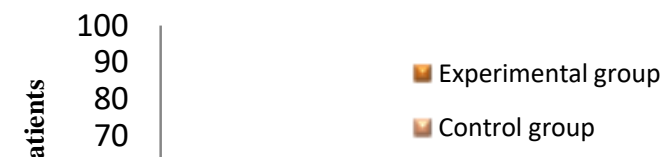

4747
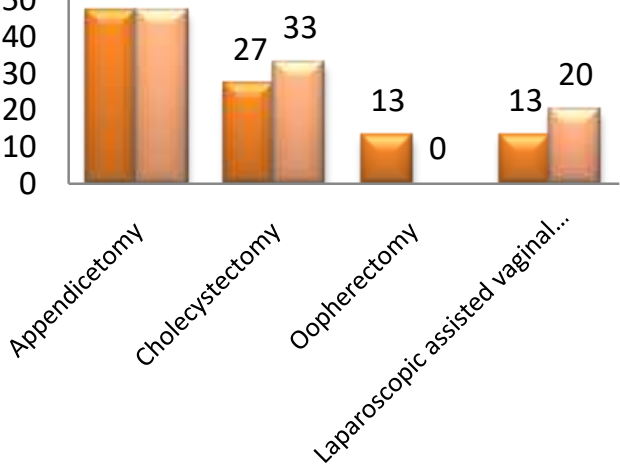

Type of surgery

Fig 4: Bar diagram showing the distribution of control and experimental group samples according to their type of surgery,
Fig 3: Bar diagram showing the distribution of control and experimental group samples according to their educational status.

Table 2: Frequency and percentage distribution of the control group and experimental group post test scores of gastric motility among post operative patients $(\mathrm{N}=30)$

\begin{tabular}{|c|c|c|c|c|}
\hline \multirow{2}{*}{$\begin{array}{c}\text { Grading of gastric } \\
\text { motility }\end{array}$} & \multicolumn{4}{|c|}{ Post test scores } \\
\cline { 2 - 5 } & Crequency (n) & Percentage (\%) & Frequency (n) & Percentage (\%) \\
\hline Absent & - & - & - & - \\
\hline Irregular & 11 & $73 \%$ & - & - \\
\hline Regular & 4 & $27 \%$ & 15 & $100 \%$ \\
\hline
\end{tabular}

Frequency and percentage distribution of control group and experimental group posttest scores of gastric motility among post operative patients depicts that, in control group most $(73 \%)$ of patients had irregular gastric motility and only $27 \%$ of patients had regular gastric motility. In experimental group all $(100 \%)$ of patients had regular gastric motility. It seems that abdominal exercise was effective in improving the gastric motility among post operative patients.

Table 3: Unpaired ' $t$ ' test value of control and experimental group post test scores of gastric motility

\begin{tabular}{|l|c|c|l|}
\hline \multicolumn{1}{|c|}{ Areas } & 't' value & Table value & \multicolumn{1}{c|}{ Level of significance } \\
\hline Bowel sound & 2.96 & 2.05 & $\mathrm{P}<0.05$ significant \\
\hline Appetite & 5.05 & 2.05 & $\mathrm{P}<0.05$ significant \\
\hline Defecation & 3.55 & 2.05 & $\mathrm{P}<0.05$ significant \\
\hline Vomiting & 1.54 & 2.05 & $\mathrm{P}>0.05$ Not significant \\
\hline TOTAL & $\mathbf{6 . 8}$ & $\mathbf{2 . 0 5}$ & $\mathrm{P}<\mathbf{0 . 0 5}$ significant \\
\hline
\end{tabular}
Df: 28
Table value $=\mathbf{2 . 0 5}$
$(\mathbf{P}>0.05$ significant $)$

Unpaired ' $\mathrm{t}$ ' test was calculated to analyze the difference in control and experimental group post test scores on different aspects of gastric motility (bowel sound, appetite, defecation and vomiting). The total score was 6.8, when compared to ' $t$ ' value (2.05) it was high. But vomiting aspect the score was 1.54 , when compared to ' $t$ ' value (2.05) is less. Hence it seems that there was significant relationship between abdominal exercise and gastric motility among post operative patients in the area of bowel sound, appetite and defecation and there was no significant relationship between abdominal exercise and gastric motility among post operative patients in the area of vomiting.

Table 4: Area wise comparison of mean, standard deviation, and mean percentage of control and experimental group post

\begin{tabular}{|c|c|c|c|c|c|c|c|c|c|}
\hline \multirow{3}{*}{$\begin{array}{l}\text { S. } \\
\text { No }\end{array}$} & \multirow{3}{*}{ Areas } & \multirow{3}{*}{$\begin{array}{l}\text { Maxi- } \\
\text { mum } \\
\text { Score }\end{array}$} & \multicolumn{6}{|c|}{ Post test scores } & \multirow{3}{*}{$\begin{array}{c}\text { Difference in mean } \\
\text { percentage }(\%)\end{array}$} \\
\hline & & & \multicolumn{3}{|c|}{ Experimental group } & \multicolumn{3}{|c|}{ Control group } & \\
\hline & & & Mean & SD & Mean $(\%)$ & Mean & SD & $\operatorname{Mean}(\%)$ & \\
\hline 2 & Appetite & 3 & 2.93 & 0.26 & 98 & 1.73 & 0.88 & 58 & 40 \\
\hline
\end{tabular}


A study to assess the Effectiveness of Abdominal exercise on Gastric motility among Post operative ..

\begin{tabular}{|l|l|c|c|c|c|c|c|c|c|}
\hline 4 & Vomiting & 3 & 3 & 0 & 100 & 2.86 & 0.35 & 95 & 5 \\
\hline & Total & $\mathbf{1 2}$ & $\mathbf{1 1 . 6}$ & $\mathbf{1 . 6 2}$ & $\mathbf{9 7}$ & $\mathbf{7 . 4 6}$ & $\mathbf{1 . 7 7}$ & $\mathbf{6 2}$ & $\mathbf{3 5}$ \\
\hline
\end{tabular}

Area wise comparison of mean, standard deviation, and mean percentage of control and experimental group post test scores depicts that, In experimental group the area of bowel sounds had the post test mean score was $(2.33 \pm 0.49)$ which was $78 \%$ whereas in control group the score was $(1.66 \pm 0.73)$ which was $55 \%$ and the mean difference percentage was $23 \%$. In experimental group the area appetite had the post test mean score was $(2.93 \pm 0.26)$ which was $98 \%$. In control group the post test mean score of appetite was $(1.73 \pm 0.88)$ which was $58 \%$ and the mean difference was $40 \%$. In experimental group the area defecation had the post test mean score was $(2.2 \pm 0.67)$ which was $73 \%$ whereas in control group the post test mean score was (1.2 \pm 0.86$)$ which was $40 \%$ and the mean difference percentage was $33 \%$.In experimental group the area vomiting had the highest mean score was $(3 \pm 0)$ which was $100 \%$ whereas in control group the mean score was $(2.86 \pm 0.35)$ which was $95 \%$ and the mean difference was 5\%. Similarly the overall experimental group the mean score was $(11.6 \pm 1.62)$ which was $97 \%$ whereas in control group the mean score was $(7.46 \pm 1.77)$ which was $62 \%$. It reveals the difference of $35 \%$. It shows that abdominal exercise is found to be effective among post operative patients. This finding concludes that abdominal exercise was found to be effective in appetite, defecation, bowel sound and vomiting among post operative patients. (fig:5)

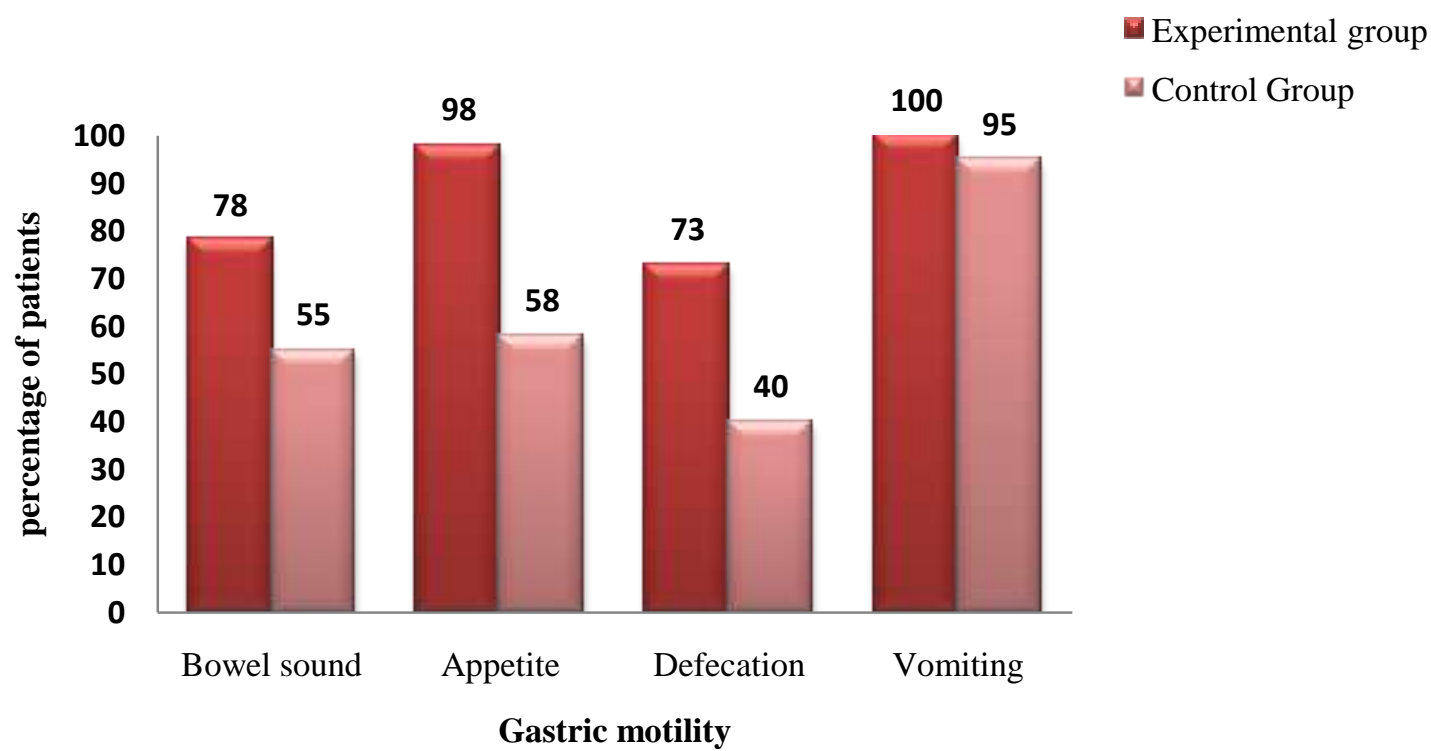

Fig: 5, Bar diagram showing the comparison of control and experimental group posttest scores on gastric motility

Table 5: chi square value of association between the demographic variables and experimental group post test scores of

\begin{tabular}{|l|c|c|c|c|}
\multicolumn{4}{c}{ gastric motility among post operative patients. } \\
\begin{tabular}{|l|c|c|c|c|}
\hline \multicolumn{1}{|c|}{ Areas } & DF & $\chi^{2}$ & TV & Level of significance \\
\hline Age & 3 & 3.22 & 7.82 & $\mathrm{P}>0.05$ Not significant \\
\hline Gender & 1 & 0.58 & 3.84 & $\mathrm{P}>0.05$ Not significant \\
\hline Education & 4 & 1.5 & 949 & $\mathrm{P}>0.05$ Not significant \\
\hline Type of surgery & 3 & 1.69 & 7.82 & $\mathrm{P}>0.05$ Not significant \\
\hline
\end{tabular}
\end{tabular}

(P > 0.05 Not significant)

Chi - square was calculated to find out the association between the experimental group post test scores of the post operative patients with their demographical variables regarding gastric motility (Age, gender, education and type of surgery) in P > 0.05 . Hence it can be interpreted that there is no significant association between post test scores of experimental group with their demographic variables.

Objective 1:

\section{Discussion}

To assess gastric motility among post operative patients in experimental and control group after abdominal exercise. The findings were,

1. In experimental group majority (67\%) of them had normal bowel sound and $33 \%$ of them had hyperactive bowel sound In control group majority (47\%) of post operative patients were found to have hypoactive bowel sound, $40 \%$ of them had normal bowel sound and $13 \%$ of them had hyperactive bowel sound. 
2. In experimental group majority (93\%) of them had good appetite and $7 \%$ of them had moderate appetite. In control group majority (40\%) of post operative patients were found to have moderate appetite, $33 \%$ of them had mild appetite, $20 \%$ of them had good appetite and $7 \%$ of them had loss of appetite.

3. In experimental group majority (54\%) of them had passed once, 33\% of them had passed more than once and $13 \%$ of them have not passed. In control group majority $(67 \%)$ of post operative patients were found to have not passed defecation, $13 \%$ of them absent of defecation and passed more than once and $7 \%$ of them had defecated once.

4. In experimental group all (100\%) of them have no vomiting. In control group majority (87\%) of post operative patients were found to have no vomiting, and $13 \%$ of them had mild vomiting.

5. In experimental group all (100\%) of them had were had regular gastric motility In control group most $73 \%$ of patients had irregular gastric motility and only $27 \%$ of patients had regular gastric motility.

\section{Hypothesis: 1}

There is a significant level of gastric motility among control and experimental group of post operative patients after abdominal exercise. So hypothesis was accepted

Objective 2:

To compare the effectiveness of abdominal exercise on gastric motility among post operative patients in experimental group with control group.

1. Unpaired ' $t$ ' test was calculated to analyze the difference in control and experimental group scores on different aspects of gastric motility (bowel sound, appetite, defecation and vomiting). The total score was 6.8, when compared to ' $t$ ' value (2.05) it was high. But vomiting aspect score was 1.54, when compared to 't' value (2.05) is less. Hence it seems that there was significant relationship between abdominal exercise and gastric motility among post operative patients in the area of bowel sound, appetite and defecation and there was no significant relationship between abdominal exercise and gastric motility among post operative patients in the area of vomiting.

2. Area wise comparison of mean, standard deviation, and mean percentage of control and experimental group post test scores depicts that, In experimental group the parameter bowel sounds has the post test mean score was (2.33 \pm 0.49$)$ which was $78 \%$ whereas in control group the post test mean score of bowel sound was $(1.66 \pm 0.73)$ which was $55 \%$ and the mean difference percentage was $23 \%$.

In experimental group the parameter appetite had the post test mean score was $(2.93 \pm 0.26)$ which was $98 \%$. In experimental group the post test mean score of appetite was (1.73 \pm 0.88$)$ which was $58 \%$ and the mean difference was $40 \%$. In experimental group the parameter defecation had the post test mean score was $(2.2 \pm 0.67)$ which was $73 \%$ whereas in control group the post test mean score was $(1.2 \pm 0.86)$ which was $40 \%$ and the mean difference percentage was $33 \%$ respectively. In experimental group the parameter vomiting had the highest mean score was $(3 \pm 0)$ which was $100 \%$ whereas in control group the mean score was $(2.86 \pm 0.35)$ which was $95 \%$ and the mean difference was $5 \%$.

Similarly the overall experimental group the mean score was (11.6 \pm 1.62$)$ which was $97 \%$ whereas in control group the mean score was $(7.46 \pm 1.77)$ which was $62 \%$. It reveals the difference of $35 \%$. It shows that abdominal exercise is found to be effective in that of post operative patients. This finding concludes that abdominal exercise was found to be effective in appetite, defecation, bowel sound and vomiting among post operative patients.

\section{Hypothesis: 2}

There is a significance effectiveness of abdominal exercise on gastric experimental group than control group. So hypothesis was accepted.

motility among post operative patients in

Objective 3:

To find out the association between post test scores of gastric motility among experimental group of post operative patients with their selected demographic variables.

Chi - square was calculated to find out the association between the experimental group post test scores of the post operative patients with their demographical variables regarding gastric motility (Age, gender, education and type of surgery) and P > 0.05 . Hence it can be interpreted that there is no significant association between post test scores of experimental group with their demographic variables.

Hypothesis: 3

There is significant association between post test scores of gastric motility among experimental group with their selected demographic variables. So the hypothesis was rejected.

\section{Conclusion}

The study findings revealed thatthe highest percentages of the patients were in the age group of 19-32 and 33-46 years, both gender were equal, most of them were educated, highest percentage patients underwent appendicectomy, abdominal exercise was highly effective on gastric motility in the area of appetite, defecation, and bowel sound. Abdominal exercise was highly effective in improving the gastric motility of the post operative patients. Therefore abdominal exercise can be used as a safe and effective method to improve gastric motility.

\section{NURSING IMPLICATIONS}

\section{Nursing Services}

1. This exercise can be used by the nursing personnel working in hospital for reinforcing their practices.

2. This method can be used in various settings.

3. This exercise can be used to demonstrate the care givers of the patients. 


\section{Nursing Education}

1. Nursing educator should educate the nursing professionals to follow this exercise and find out the effectiveness.

2. The nursing curriculum concentrates more on abdominal exercise when formulating syllabus.

\section{Nursing administration:}

1. Nursing administrator can influence quality of nursing care in hospital setting community by planning and supervising health education in different level

2. Administrative staff should understand the felt need of post operative patients.

3. Nursing administrator can organise conferences, seminars, and workshops for nurses working in the hospital to encourage a positive attitude on abdominal exercise.

Nursing Research

1. The result of this study encourage the nurse to adopt this as a part their nursing intervention in providing a holistic care to the patients.

\section{Recommendations}

Based on the findings of the study the following recommendations have been made for the study.

- A large scale study can be carried out to generalize the findings.

- A similar study can be conducted to all post operative patients.

- A similar study can be conducted to see the effectiveness of abdominal breathing exercise on gastric motility among post operative patients.

- A comparative study can be conducted to assess the effectiveness of abdominal breathing vs Vajarasana on gastric motility among post operative patients

- A similar study can be conducted with planned teaching program, self instructional module and compact disc.

\section{References}

[1]. Barbara Kozier et.al, (1999) 'Fundamentals of Nursing Concepts, Process and Practice, ( $7^{\text {th }}$ edition), J.B.Lippincott company, Philadelphia

[2]. Black M Joyce and Hawks Hokanson (2005), "Medical Surgical Nursing", ( $7^{\text {th }}$ edition), W B Saunders company; Missouri.

[3]. Brunner and Suddarth's.(2000), "Text book of Medical Surgical Nursing', $9^{\text {th }}$ edition. Lippincott Williams and Wilkins publication, Newyork.

[4]. Christensen Barbara and Kockhow Elaine (1995) "Foundation of Nursing”, (2 ${ }^{\text {nd }}$ edition), Lippincott Company; Philadelphia.

[5]. Denise,F.Polit., Bernadette,P.Hungler.(1999).Nursing Research principles and methods. th $^{\text {th }}$ edition. Lippincott William and Wilkins publications. Newyork.

[6]. Denise,F.Polit., Cheryl Tatano, Beck.(2002). Nursing Research principles and methods. $7^{\text {th }}$ edition. Lippincott William and Wilkins publication. Newyork.

[7]. Hungler B P and Polit Denise F(1999), “Nursing Research"' Lippincott Company, Philadelphia

[8]. Lewis Sharon Mantik et.al.,(2004), "Medical Surgical Nursing”,(3 $3^{\text {rd }}$ edition), Mosby Publication;Philadelphia.

[9]. Long Phipps and Cassvever, (1993), "Medical Surgical Nursing-A Nursing Process Approach" ( $3{ }^{\text {rd }}$ edition), Mosby Publication,

[10]. Missouri.Potter A Patricia and Perry Anne Griffin, (2005), “Fundamentals Of Nursing”, (6 $6^{\text {th }}$ edition),Mosby publication; Missouri

[11]. Roberta C.Weoss, (1999), “Physical Therapy Aide: A Worktect”, $2^{\text {nd }}$ edition, Delmar Publishers;

[12]. Toronto.Sundar Rao and Richard J(2000), “An Introduction to Biostatistics” ( $5^{\text {th }}$ edition), Prentice Hall; New Delhi.

[13]. Susan C Dewit, (1994), “Rambo's Nursing Skills for clinical Practice'”( $4^{\text {th }}$ edition), W.B. Saunder's Company, Philadelphia.

[14]. Taylor C et.al.,(1993), “Fundamentals Of Nursing”'(2 ${ }^{\text {nd }}$ edition),J B Lippincott Company; Philadelphia.

\section{JOURNALS}

[15]. Altman DG.( 1991) Practical Statistics for Medical Research. Chapman \& Hall: London, 3(4): 455 460

[16]. Charoenkwan K, Phillipson G, Vutyavanich T.(2008) statistic review Evid Based Nursing,11(2):56.

[17]. E. E.Soffer, R. W. Summers and C. Gisolfi(2004), Effect of exercise on intestinal motility and transit in trained athletes, Medicine, 42(1).22-24.

[18]. Tranmer J E, Minard J, Fox L A, Rebelo L,(2003), “Clinical Nursing Research, 12(2), 159-173.

[19]. Van Nieuwenhoven MA, Brouns F, Brummer RJ. (1999) The effect of physical exercise on parameters of gastrointestinal function. Neurogastroenterol Motil. ;11(6):431-9.

\section{NET REFERENCE}

[20]. www.google.com

[21]. www.yahoo.com

[22]. www.pubmed.com

[23]. www.msn.com

[24]. www.answer.com

[25]. www.mediscape.co.in

[26]. www.doctorgendron.com

[27]. www.aiternativetherapies.com

[28]. www.sciencedirect.com

[29]. www.discovernursing.com

[30]. www.laparoscopysurgeryindiasite.com

[31]. www.medindia.net

[32]. www.nlm.nih.gov

[33]. www.midwestsurgicalservices.com 